\title{
Gas chromatography-mass spectrometry analysis, phytochemical screening and antiprotozoal effects of the methanolic Viola tricolor and acetonic Laurus nobilis extracts
}

\author{
Gaber El-Saber Batiha ${ }^{1,2^{*}+}$ (D), Amany Magdy Beshbishy ${ }^{1 \dagger}$, Luay Alkazmi ${ }^{3}$, Oluyomi Stephen Adeyemi ${ }^{4}$, \\ Eman Nadwa ${ }^{5,6}$, Eman Rashwan ${ }^{7,8}$, Amany El-Mleeh ${ }^{9}$ and Ikuo Igarashi ${ }^{1}$
}

\begin{abstract}
Background: The antiprotozoal and antioxidant activities of Viola tricolor and Laurus nobilis have been reported recently. Thus, the existing study pursued to assess the growth inhibition effect of methanolic extract of $V$. tricolor (MEVT) and acetonic extract of L. nobilis (AELN) against five Babesia parasites and Theileria equi in vitro and in vivo.

Results: MEVT and AELN suppressed Babesia bovis, B. bigemina, B. divergens, B. caballi, and T. equi growth at halfmaximal inhibitory concentration $\left(I C_{50}\right)$ values of $75.7 \pm 2.6,43.3 \pm 1.8,67.6 \pm 2.8,48 \pm 3.8,54 \pm 2.1 \mu \mathrm{g} / \mathrm{mL}$, and $86.6 \pm$ $8.2,33.3 \pm 5.1,62.2 \pm 3.3,34.5 \pm 7.5$ and $82.2 \pm 9.3 \mu \mathrm{g} / \mathrm{mL}$, respectively. Qualitative phytochemical estimation revealed that both extracts containing multiple bioactive constituents and significant amounts of flavonoids and phenols. The toxicity assay revealed that MEVT and AELN affected the mouse embryonic fibroblast (NIH/3 T3) and MadinDarby bovine kidney (MDBK) cell viability with half-maximum effective concentrations (EC ${ }_{50}$ ) of $930 \pm 29.9,1260 \pm$ $18.9 \mu \mathrm{g} / \mathrm{mL}$, and $573.7 \pm 12.4,831 \pm 19.9 \mu \mathrm{g} / \mathrm{mL}$, respectively, while human foreskin fibroblasts (HFF) cell viability was not influenced even at $1500 \mu \mathrm{g} / \mathrm{mL}$. The in vivo experiment revealed that the oral administration of MEVT and AELN prohibited B. microti multiplication in mice by 35.1 and $56.1 \%$, respectively.
\end{abstract}

Conclusions: These analyses indicate the prospects of MEVT and AELN as good candidates for isolating new antiprotozoal compounds which could assist in the development of new drug molecules with new drug targets.

Keywords: Drug discovery, Medicinal biochemistry, Natural products, Parasitic diseases

\section{Background}

Piroplasms, the causative factors of piroplasmosis, are among the most prevalent blood parasites in the world and therefore show a significant economic, medical and veterinary impact all over the world $[1,2]$. The problems

\footnotetext{
* Correspondence: dr_gaber_batiha@vetmed.dmu.edu.eg;

gaberbatiha@gmail.com

${ }^{\dagger}$ Gaber El-Saber Batiha and Amany Magdy Beshbishy contributed equally to this work.

${ }^{1}$ National Research Center for Protozoan Diseases, Obihiro University of Agriculture and Veterinary Medicine, Nishi 2-13, Inada-cho, Obihiro, Hokkaido 080-8555, Japan

${ }^{2}$ Department of Pharmacology and Therapeutics, Faculty of Veterinary Medicine, Damanhour University, Damanhour, AlBeheira 22511, Egypt Full list of author information is available at the end of the article
}

of parasite resistance, as well as the toxic residues to most of the commercially available antipiroplasmic drugs (diminazene aceturate (DMA), atovaquone (ATV), clindamycin, imidocarb dipropionate, azithromycin, and quinine) severely weaken their effective curative and protective approaches $[3,4]$. Therefore, it is clear that the development of treatment options for piroplasmosis is vital for improving disease treatment and control.

Up to date, medicinal plants have been documented as an important source for discovering new pharmaceutical molecules that have been used to treat serious diseases $[3,5,6]$. Strikingly, previous reports stated that natural products and their derived compounds exhibit lesser side 
effects and improved efficacy than other synthetic counterparts [7]. Many plant species have been reported to have pharmacological activities attributable to their phytoconstituents such as glycosides, saponins, flavonoids, steroids, tannins, alkaloids, terpenes and accordingly.

Viola tricolor L., Sp. Pl. 935 (1753) (V. tricolor) (Mnemion tricolor (L.) Spach (1836), China violet, family Violaceae) is a genus of the flowering plants that have been used traditionally to treat many diseases such as bruises, fever, cough, flu, ulcers, malaria, and cancer [8-11]. Furthermore, its edible flowers have been reported for their importance to human health because of their richness in biologically active compounds [12-14]. It is worth noting that, 35 compounds have been previously reported for $V$. tricolor namely: 17 aliphatics, 8 sesquiterpenes, 4 monoterpenes, and 6 shikimic acid derivatives, in addition to the presence of bisabolol oxide A and B, bisabolene oxide and trans- $\beta$-farnesene volatile components $[15,16]$. Moreover, $V$. tricolor contains 164 cyclotides, a plant cyclopeptide that is distinguished by cyclic cysteine-knot (CCK) motif, which occur naturally in many plants and possess numerous bioactivities including anthelmintic, molluscicidal, insecticidal, antimicrobial, hemolytic, anti-HIV, cytotoxic, immunosuppressive, and trypsin inhibitory activities [13, 17-20]. Moon et al. [21] studied the antimalarial effect of Viola petroleum ether extracts and its active component epi-oleanolic acid toward Plasmodium falciparum chloroquineresistant $F c B 1$ strain. The Viola extracts showed high growth inhibition against Leishmania donovani, Trypanosoma cruzi and P. falciparum with $\mathrm{IC}_{50}$ values of 0.40 , 1.86 and $2.76 \mu \mathrm{g} / \mathrm{mL}$, respectively [5].

Laurus nobilis L., Sp. Pl. 369 (1753) (L. nobilis) (Laurus undulata Miller (1768)) is one of the most wellknown herbs of the Lauraceae family that is also known as Bay or laurel leaves, and are frequently used in the traditional health care system [7, 22, 23]. Phytochemical studies on Bay leaves and its fruits have indicated various secondary metabolites including alkaloids, flavonols (kaempferol, myricetin, and quercetin), flavones (apigenin and luteolin), glycosylated flavonoids, sesquiterpene lactones, monoterpene, and germacrene alcohols. The main components isolated from L. nobilis were eugenol, elemicin, methyl eugenol, and $\alpha$-terpinyl acetate [24]. Moreover, the phytochemical reports showed that leaves of $L$. nobilis possess sabinene, linalool, and 1, 8cineole [25-27]. Traditionally, L. nobilis leaves have been used to treat gastrointestinal symptoms, such as eructation, epigastric bloating, impaired digestion and flatulence [28-30]. Fidan et al. [31] examined and proved the antimicrobial effects of the alcoholic extracts of $L$. nobilis and its essential oil. Ozcan et al. [6] documented the effectiveness of $L$. nobilis extracts in the treatment of rheumatoid arthritis and indigestion, as an antiseptic, a diaphoretic, and a diuretic. Moreover, their antioxidant property has been associated with the existence of methyl eugenol, elemicin and eugenol [24, 32].

Although $V$. tricolor and $L$. nobilis have been reported for several medicinal values, there is no evidence on their antipiroplasmic activity. Thus, the current study examined the effectiveness of methanolic extract of $V$. tricolor (MEVT) and acetonic extract of $L$. nobilis (AELN) on the multiplication of T. equi, B. bigemina, $B$. bovis, $B$. caballi and $B$. divergens using the in vitro fluorescence assay and their chemotherapy prospects against B. microti-infected mice.

\section{Methods}

\section{Ethical statement}

The in vivo experiments were performed in conformity with the local guidelines for animal experiments, as approved by the Obihiro University of Agriculture and Veterinary Medicine, Japan (accession number of the animal experiment: 28-111-2/28-110). This ethical approval was developed through the basic guidelines for the proper conduct of animal experimentation and related activities in Academic Research Institutions, Ministry of Education, Culture, Sports and Technology (MEXT), Japan.

\section{The chemical reagents}

Stock solutions (100 mg (crude extract) / $1 \mathrm{~mL}$ (DMSO) and $10 \mathrm{mM}$ ) in dimethyl sulfoxide (DMSO) of crude extract and DMA (Ciba-Geigy Japan limited, Tokyo, Japan) and ATV (Sigma-Aldrich, Japan), respectively were stored at $-30{ }^{\circ} \mathrm{C}$ and used for antibabesiosis evaluation. Reference drugs (DMA and ATV) were used either singly and/or in combination with the two extracts for both the in vivo and in vitro experiments. For the fluorescence assay, SYBR Green I (SGI) stain (10,000×, Lonza, USA) was mixed with the lysis buffer containing saponin $(0.016 \% \mathrm{w} / \mathrm{v})$, EDTA $(10 \mathrm{mM})$, Triton X-100 (1.6\% v/v), and Tris $(130 \mathrm{mM}$ at $\mathrm{pH} 7.5)$ which was filtered using a polyethersulfone $(0.22 \mu \mathrm{m})$ and kept at $4{ }^{\circ} \mathrm{C}$.

\section{Herbal plants}

$V$. tricolor flower and L. nobilis leaves were gathered from Delta, North part of Egypt from June 2016 to August 2016 and identified by the members of the Pharmacology and Chemotherapeutics Department, Faculty of Veterinary Medicine, Damanhour University, Egypt. $V$. tricolor and $L$. nobilis voucher specimen numbers are A0177103 (DPV) and A0177104 (DPV), respectively. An electric dryer (Sanyo Electric Co., Ltd., Osaka, Japan) was used to dry the plants at a temperature of $30{ }^{\circ} \mathrm{C}$, then ground using a $60-80 \mathrm{~mm}$ mesh to a fine powder. Subsequently, fine plant powder $(100 \mathrm{~g})$ was extracted using methanol (99.8\%) (Wako pure chemical Industrial, 
Ltd., Osaka, Japan) or acetone (99.5\%) (Nacalai Tesque, Kyoto, Japan) $(50 \mathrm{~mL})$ and incubated for $72 \mathrm{~h}$ at a temperature of $30^{\circ} \mathrm{C}$. The preparation of slurry extract was performed following the method as previously described $[3,33,34]$ and the extracted stock $(100 \mathrm{mg} / 1$ $\mathrm{mL}$ DMSO) was stored at $-30^{\circ} \mathrm{C}$ and used for antibabesial evaluation. The obtained extracts of the MEVT and AELN weight were 7.09 and $7.25 \mathrm{~g}$, respectively, and the yield percentage was measured using the following formula [35]:

Percentage yield of extracts $=\frac{\text { Weight of the obtained extract material }}{\text { Weight of original fine plant powder used }} \times 100$

\section{Phytochemical examination of plant extracts}

MEVT and AELN were examined for the existence of terpenoids, saponins, tannins, and alkaloids using several qualitative tests as previously reported elsewhere [36].

\section{Determination of total phenolic material}

The total phenolic material concentration present in MEVT and AELN was detected using Folin-Ciocalteu (FC) assay as described elsewhere [37]. A volume of $500 \mu \mathrm{L}$ of both extracts $(1 \mathrm{mg} / \mathrm{mL})$ was added to $1.5 \mathrm{~mL}$ of $10 \%$ FC reagent and mixed for $5 \mathrm{~min}$. After that, the reaction mixture was further incubated for an additional $2 \mathrm{~h}$ after the addition of aliquot $(3 \mathrm{~mL})$ of $7.5 \% \mathrm{Na}_{2} \mathrm{CO}_{3}$ solution. Finally, the absorbance was calculated at 760 $\mathrm{nm}$ and the total phenolic compounds were detected from a gallic acid standard curve and expressed as $\mathrm{mg} / \mathrm{g}$ gallic acid equivalent (GAE) of the dry weight of the extract (mg GAE/g DW).

\section{Determination of total flavonoid material}

Aluminium chloride $\left(\mathrm{AlCl}_{3}\right)$ colorimetric assay was used for the examination of total flavonoid material in MEVT and AELN as previously determined [37]. Briefly, an aliquot $(1 \mathrm{~mL})$ of both extracts was added to $3 \mathrm{~mL}$ of solvent extracts, $3.8 \mathrm{~mL}$ of distilled water, $200 \mu \mathrm{L}$ of $1 \mathrm{M}$ potassium acetate and $200 \mu \mathrm{L}$ of $10 \% \mathrm{AlCl}_{3}$ and incubated for $30 \mathrm{~min}$. The flavonoid content was detected from a catechin standard curve after measuring the absorbance at $420 \mathrm{~nm}$ and expressed as $\mathrm{mg} / \mathrm{g}$ catechin equivalents of the dry weight of individual extract (mg CAE/g DW).

Gas chromatography-mass spectrometry (GC-MS) analysis The chemical composition of MEVT and AELN was performed using Trace GC-ISQ mass spectrometer (Thermo Scientific, Austin, TX, USA) with a direct capillary column TG-5MS $(30 \mathrm{~m} \times 0.25 \mathrm{~mm} \times 0.25 \mu \mathrm{m}$ film thickness) as previously described [38, 39]. The column oven temperature was initially held at $50^{\circ} \mathrm{C}$ and then increased by $5{ }^{\circ} \mathrm{C} / \mathrm{min}$ to $250^{\circ} \mathrm{C}$ withhold $1 \mathrm{~min}$ then increased to 300 at the rate of $30^{\circ} \mathrm{C} / \mathrm{min}$. The injector temperatures were kept at $260^{\circ} \mathrm{C}$. Helium was used as a carrier gas at a constant flow rate of $1 \mathrm{~mL} / \mathrm{min}$. The solvent delay was $4 \mathrm{~min}$ and diluted samples of $1 \mu \mathrm{L}$ were injected automatically using an AS3000 Autosampler coupled with GC in the split mode. EI mass spectra were collected at $70 \mathrm{eV}$ ionization voltages over the range of $m / z 50-650$ in full scan mode. The ion source and transfer line were set at $250^{\circ} \mathrm{C}$ and $270{ }^{\circ} \mathrm{C}$, respectively. The components were identified by comparison of their retention times and mass spectra with those of WILEY 09 and NIST 11 mass spectral databases.

\section{Parasites and mice}

For the in vitro experiments, a German strain $B$. divergens, Argentine strain B. bigemina, Texas strain B. bovis, were cultivated in cattle RBCs, while USDA strains of equine piroplasm parasites (T. equi and B. caballi) were maintained in horse RBCs [34]. The parasite incubation occurred at $37{ }^{\circ} \mathrm{C}$ in a humidifying chamber under $90 \%$ $\mathrm{N}_{2}, 5 \% \mathrm{O}_{2}$, and $5 \% \mathrm{CO}_{2}$ atmosphere using a microaerophilic stationary-phase culture. For conducting the in vivo study, female BALB/c mice, aged six-week, obtained from CLEA Japan were infected with B. microti Munich strain [1].

\section{In vitro cultivation of parasites}

Roswell Park Memorial Institute (RPMI) 1640 medium (Sigma-Aldrich, Tokyo, Japan) replenished with 40\% cattle serum and used as a growth medium for $B$. divergens parasite culture and culture medium 199 (M199) was used as a growth medium for B. bigemina and B. bovis replenished with $40 \%$ cattle serum. While $T$. equi was grown in M199 complemented with 40\% horse serum containing hypoxanthine (MP Biomedicals, USA; final concentration $13.6 \mu \mathrm{g} / \mathrm{mL}$ ). GIT medium replenished with $40 \%$ horse serum was used as a growth medium for B. caballi parasite culture. To ensure free-bacterial contamination, all medium was supplemented with amphotericin B $(0.15 \mu \mathrm{g} /$ $\mathrm{mL})$ (Sigma-Aldrich, USA), streptomycin $(60 \mathrm{U} / \mathrm{mL})$ and penicillin $\mathrm{G}(60 \mathrm{U} / \mathrm{mL})$.

\section{Assessment of the impacts of MEVT and AELN on RBCs of host}

Prior to parasite subculture, $400 \mu \mathrm{g} / \mathrm{mL}$ of MEVT and AELN were mixed with fresh bovine and equine RBCs and incubated at a humidifying incubator for $3 \mathrm{~h}$. Then B. bovis and T. equi-infected RBCs (iRBCs) were washed thrice with PBS and mixed with the pretreated-RBCs to achieve $1 \%$ parasitemia. Thereafter, using a 24-well plate, an aliquot of iRBCs $(100 \mu \mathrm{L})$ was mixed with culture media $(900 \mu \mathrm{L})$; the control RBCs were left untreated. To monitor the parasitemia and any side effects due to 
the pretreatment, Giemsa-stained smears were prepared every $24 \mathrm{~h}$ for 4 days.

\section{The inhibition assay of MEVT and AELN in vitro}

The Babesia fluorescent assay was carried out on the in vitro culture as previously reported elsewhere [3]. Briefly, in three separate trials, using two-fold dilution, different concentrations MEVT, AELN, DMA, and ATV were prepared in the culture medium and added in 96well plates in triplicate with $1 \%$ parasitemia for equine piroplasm parasites (T. equi and B. caballi) and B. divergens at $5 \%$ hematocrit (HCT), while for B. bigemina and $B$. bovis using $2.5 \%$ HCT. The positive control had iRBCs with final concentration of $0.2 \%$ of DMSO, whereas uninfected RBCs with medium served as the negative control. Afterward, parasite cultures were incubated for 4 consecutive days without changing medium at $37^{\circ} \mathrm{C}$ humidifying incubator in $90 \% \mathrm{~N}_{2}, 5 \% \mathrm{O}_{2}$, and $5 \% \mathrm{CO}_{2}$ atmosphere. On day four of culture, an aliquot $(100 \mu \mathrm{L})$ of lysis buffer was added to $0.2 \mu \mathrm{L} / \mathrm{mL}$ SG1 per well; subsequently, it was covered with aluminum foil to prevent exposure to light. After a 6-h incubation at $37^{\circ} \mathrm{C}$, fluorescence readings were acquired on a spectrofluorimeter (Fluoroskan Ascent, Thermo Fisher Scientific, USA) with a $485 \mathrm{~nm}$ excitation wavelength and a $518 \mathrm{~nm}$ emission wavelength.

\section{Parasite viability test in vitro}

The viability studies were monitored via microscopy as described elsewhere $[1,33]$. Briefly, an aliquot $(20 \mu \mathrm{L})$ of infected RBCs (1\% parasitemia) was cultivated in $200 \mu \mathrm{L}$ of media containing various concentrations of MEVT and AELN for 4 successive days, changing media daily. The concentrations used in this experiment were $0.25 \times$, $0.5 \times, 1 \times, 2 \times$, and $4 \times$ the $\mathrm{IC}_{50}$. On the fifth day, a mixture of iRBCs $(6 \mu \mathrm{L})$ from each well and fresh equine or bovine RBCs $(14 \mu \mathrm{L})$ was transferred to another plate, cultured in a medium free from drug and then left for an additional 6 days. The total parasite clearance was recorded as negative, while the relapse of parasites was recorded as positive.

\section{Cell lines cultivation}

Cultures of Human foreskin fibroblast (HFF; HFF-1 ATCC ${ }^{\circ}$ SCRC-1041 $1^{\mathrm{mm}}$ ), Madin-Darby bovine kidney (MDBK; ECACC) and mouse embryonic fibroblast (NIH/ 3 T3; $\mathrm{ATCC}^{\circ} \mathrm{CRL}^{-1658^{\mathrm{mm}}}$ ) cells were retrieved from $80^{\circ} \mathrm{C}$ stock and cultured continuously at $37^{\circ} \mathrm{C}$ under atmosphere $5 \% \mathrm{CO}_{2}$ in our laboratory. The NIH/3 T3 and HFFs cells were preserved in Dulbecco Modified Eagle's Medium (DMEM; Gibco, Grand Island, NY, USA), while MDBK cell line grown in Minimum Essential Medium Eagle (MEM; Gibco). All mediums were treated with 2 $\mathrm{mM}$ glutamine, $0.5 \%$ penicillin/streptomycin (Gibco) and
$10 \%$ inactivated fetal bovine serum. Every 72 to $96 \mathrm{~h}$, the medium was replaced, and once $80 \%$ confluence was reached, the cell collection was performed by sub-culture protocol. To confirm the absence of mycoplasma contamination, 4, 6-diamidino-2-phenylindole dihydrochloride (Sigma-Aldrich, USA) stain was used [3, 33].

\section{Cytotoxicity assay of MEVT and AELN on normal cells}

The cell viability test was conducted in a 96-well plate as described elsewhere [2, 39]. Briefly, an aliquot of $(100 \mu \mathrm{L})$ cells was implanted at $5 \times 10^{4}$ cells $/ \mathrm{mL}$ in DMEM or MEM with fetal bovine serum and incubated overnight under atmosphere $5 \% \mathrm{CO}_{2}$ at $37^{\circ} \mathrm{C}$ for attachment. Using two-fold dilutions, aliquots $(10 \mu \mathrm{L})$ of herbal extracts and reference drugs were added in triplicate per well and further incubated for $24 \mathrm{~h}$. The positive control wells containing cells mixed with the medium in $0.4 \%$ DMSO, whereas the negative control wells containing culture medium only. After a 24-h incubation, Cell Counting Kits-8 (CCK-8) $(10 \mu \mathrm{L})$ was added per well and then plate incubation was conducted for an additional $3 \mathrm{~h}$ and a microplate reader was used to assess the absorbance at $450 \mathrm{~nm}$.

\section{In vitro combination treatment of MEVT and AELN with DMA and ATV}

Combination therapies of MEVT and AELN with DMA and ATV were tested using the fluorescence inhibition method as reported elsewhere $[40,41]$. Five selected dilutions $\left(0.25 \times, 0.5 \times, 1 \times, 2 \times\right.$ and $4 \times$ the $\left.\mathrm{IC}_{50}\right)$ of the two herbal extracts with DMA and ATV were set up in three sets of duplicate wells and the parasite cultures were incubated for four consecutive days at $37^{\circ} \mathrm{C}$ humidifying incubator in $90 \% \mathrm{~N}_{2}, 5 \% \mathrm{O}_{2}$, and $5 \% \mathrm{CO}_{2}$ atmosphere without changing medium. The drug cultivation and the fluorescence values were detected after the addition of $2 \times$ SGI mixed with lysis buffer to each well of the 96-well plate as described above. CompuSyn software was used for combination index (CI) values calculation and the synergetic degree was established as the average weighted $\mathrm{CI}$ values by using the following formulae; $\left[\left(1 \times \mathrm{IC}_{50}\right)+\left(2 \times \mathrm{IC}_{75}\right)+\left(3 \times \mathrm{IC}_{90}\right)+\left(4 \times \mathrm{IC}_{95}\right)\right] / 10$ and the resulted values were demonstrated using the recommended CI scale; lower than 0.90 was considered synergetic, between $0.90-1.10$ was considered additive, while higher than 1.10 was considered antagonistic developed previously [40, 41].

\section{Chemotherapeutic effects of MEVT and AELN against $B$. microti}

MEVT and AELN were examined for its in vivo chemotherapeutic effectiveness using $B$. microti-infected BALB/ $\mathrm{C}$ mice according to a procedure described elsewhere [1]. Twenty-five mice were placed in an environment free 


\section{Methanolic Viola tricolor}

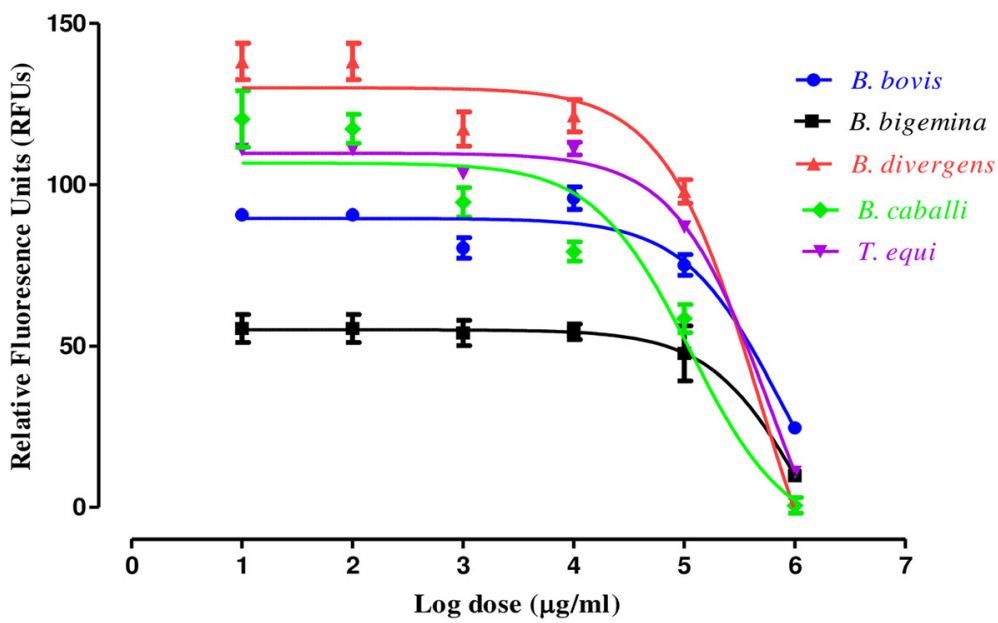

Fig. 1 The relationship between the relative fluorescence units (RFUs) and the log concentrations of methanolic $V$. tricolor (MEVT) ( $\mu \mathrm{g} / \mathrm{mL})$ on $T$. equi, B. divergens, B. bigemina, B. caballi, and B. bovis. The non-linear regression (curve fit analysis) in GraphPad Prism software (GraphPad Software Inc. USA) used for $I_{50}$ 's calculation. The percentage of parasite growth inhibitory efficacy is calculated as the percentage of parasites inhibited divided by that of the positive control wells and the result was subtracted from the negative control wells

from pathogens with $22^{\circ} \mathrm{C}$ temperature and adjusted humidity and under $12 \mathrm{~h}$ light and $12 \mathrm{~h}$ darkness and randomly distributed into five groups. The mice in groups 2 through 5 were obtained $500 \mu \mathrm{L}$ of $1 \times 10^{7}$ B. microti iRBC by intraperitoneal (i.p.) injection. Group 1 served as a negative control and was neither infected nor treated. At $1 \%$ parasitemia, drug treatment of the mice by i.p. started, continuing for 5 days. Group 2 act as a positive control group and received 95\% DDW and 5\% DMSO. Group 3 was served as the reference drug control and received $25 \mathrm{mg} \mathrm{kg}^{-1}$ body weight (BW) of DMA, while groups 4 and 5 obtained $150 \mathrm{mg} \mathrm{kg}^{-1} \mathrm{BW}$ of MEVT and AELN orally using oral gavage injection syringe, respectively. The drug administration lasted for 5 days starting from the fourth day to the eighth day postinfection (p.i.), and parasitemia was checked by preparing Giemsa-stained smears every 2 days in about 2000 RBCs by microscopy until day 32 post-infection

\section{Acetonic Laurus nobilis}

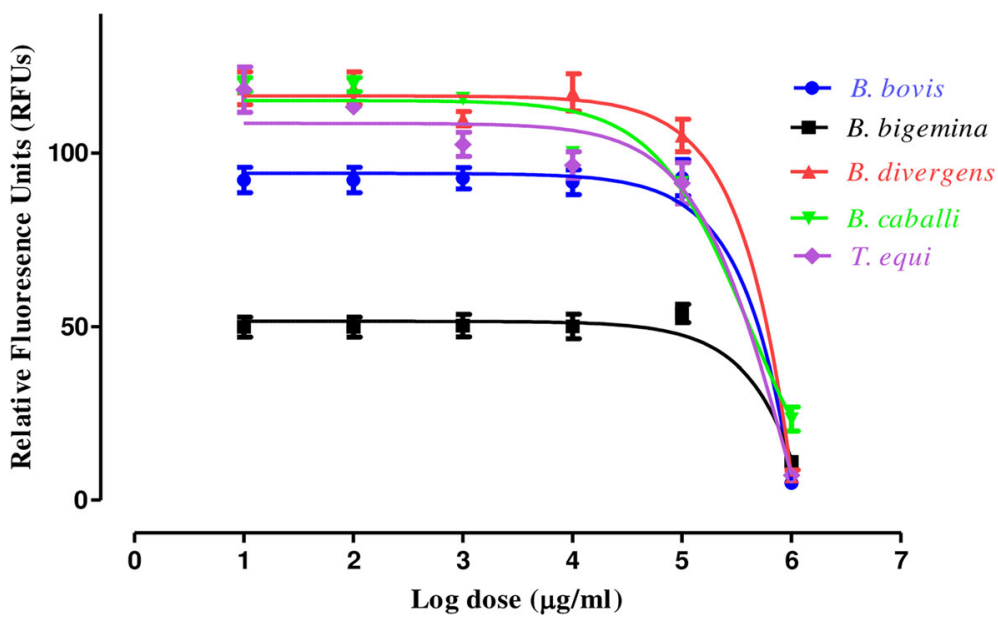

Fig. 2 The relationship between the relative fluorescence units (RFUs) and the log concentrations of acetonic L. nobilis (AELN) ( $\mu \mathrm{g} / \mathrm{mL})$ on T. equi, B. divergens, B. bigemina, B. caballi, and B. bovis. The non-linear regression (curve fit analysis) in GraphPad Prism software (GraphPad Software Inc. USA) used for I $C_{50}$ 's calculation. The percentage of parasite growth inhibitory efficacy is calculated as the percentage of parasites inhibited divided by that of the positive control wells and the result was subtracted from the negative control wells 
Table $1 \mathrm{IC}_{50}$ and selective index values of methanolic Viola tricolor and acetonic Laurus nobilis extracts

\begin{tabular}{|c|c|c|c|c|c|c|c|c|}
\hline \multirow{2}{*}{$\begin{array}{l}\text { Crude } \\
\text { extract }\end{array}$} & \multirow{2}{*}{$\begin{array}{l}\text { Babesia and } \\
\text { Theileria }\end{array}$} & \multirow{2}{*}{$\begin{array}{l}\mathrm{IC}_{50}(\mu \mathrm{g} / \\
\mathrm{mL})^{\mathrm{a}}\end{array}$} & \multicolumn{3}{|c|}{$\mathrm{EC}_{50}(\mu \mathrm{g} / \mathrm{mL})^{\mathrm{b}}$} & \multicolumn{3}{|c|}{ Selective indices ${ }^{c}$} \\
\hline & & & MDBK & $\mathrm{NIH} / 3 \mathrm{T3}$ & HFF & MDBK & $\mathrm{NIH} / 3 \mathrm{T3}$ & HFF \\
\hline \multirow[t]{5}{*}{ MEVT } & B. bovis & $75.7 \pm 2.6$ & $930 \pm 29.9$ & $1260 \pm 18.9$ & $>1500$ & 12.3 & 16.7 & $>19.8$ \\
\hline & B. bigemina & $43.3 \pm 1.8$ & $930 \pm 29.9$ & $1260 \pm 18.9$ & $>1500$ & 21.5 & 29.1 & $>34.6$ \\
\hline & B. divergens & $67.6 \pm 2.8$ & $930 \pm 29.9$ & $1260 \pm 18.9$ & $>1500$ & 13.8 & 18.6 & $>22.2$ \\
\hline & B. caballi & $48 \pm 3.8$ & $930 \pm 29.9$ & $1260 \pm 18.9$ & $>1500$ & 19.4 & 26.3 & $>31.3$ \\
\hline & T. equi & $54 \pm 2.1$ & $930 \pm 29.9$ & $1260 \pm 18.9$ & $>1500$ & 17.2 & 23.3 & $>27.8$ \\
\hline \multirow[t]{5}{*}{ AELN } & B. bovis & $86.6 \pm 8.2$ & $573.7 \pm 12.4$ & $831 \pm 19.9$ & $>1500$ & 6.6 & 9.6 & $>17.3$ \\
\hline & B. bigemina & $33.3 \pm 5.1$ & $573.7 \pm 12.4$ & $831 \pm 19.9$ & $>1500$ & 17.2 & 25 & $>45.1$ \\
\hline & B. divergens & $62.2 \pm 3.3$ & $573.7 \pm 12.4$ & $831 \pm 19.9$ & $>1500$ & 9.2 & 13.4 & $>24.1$ \\
\hline & B. caballi & $34.5 \pm 7.5$ & $573.7 \pm 12.4$ & $831 \pm 19.9$ & $>1500$ & 16.6 & 24.1 & $>43.5$ \\
\hline & T. equi & $82.2 \pm 9.3$ & $573.7 \pm 12.4$ & $831 \pm 19.9$ & $>1500$ & 7 & 10.1 & $>18.2$ \\
\hline
\end{tabular}

${ }^{\mathrm{a}} \mathrm{C}_{50}$ values of MEVT and AELN on all tested parasites in vitro. ${ }^{\mathrm{b}} \mathrm{EC} \mathrm{C}_{50}$ values of MEVT and AELN on the tested cell lines. The dose-response curve using nonlinear regression (curve fit analysis) was used to detect all of these values. The values obtained from the means of triplicate experiments. 'Selective index calculated as the ratio between the concentration that causes safety problems in cell lines and the concentration that is used for efficacy in each parasite

(p.i.). Furthermore, the hematological parameters, including hemoglobin (HGB), RBCs, and HCT, were determined by an automatic hematology analyzer (Celltac $\alpha$ MEK-6450, Nihon Kohden, Japan) every 4 days. After finishing the in vivo experiment, an anesthetic system using an inhaler containing isoflurane was used to euthanize all mice by placing them in the induction chamber, adjusting the oxygen flowmeter to 0.8 to $1.5 \mathrm{~L} / \mathrm{min}$ and vaporizer to 3 to $5 \%$. When mice were completely anesthetized, all of them were killed by cervical dislocation according to the ethical approval confirmed by the Basic Guidelines for Proper Conduct of Animal Experiment and Related
Activities in Academic Research Institutions, the Ministry of Education, Culture, Sports and Technology (MEXT), Japan.

\section{Data analysis}

The $\mathrm{IC}_{50}$ values of the two extracts, DMA and ATV were established from the in vitro growth inhibition by nonlinear regression curve fit on a GraphPad Prism (GraphPad Software Inc., USA). While for in vivo, the significant variations $(p<0.05)$ among group mean values on parasitemia and one-way ANOVA Tukey's test in GraphPad Prism version 5.0 was used to analyze hematology profiles in mice infected with $B$. microti [3].

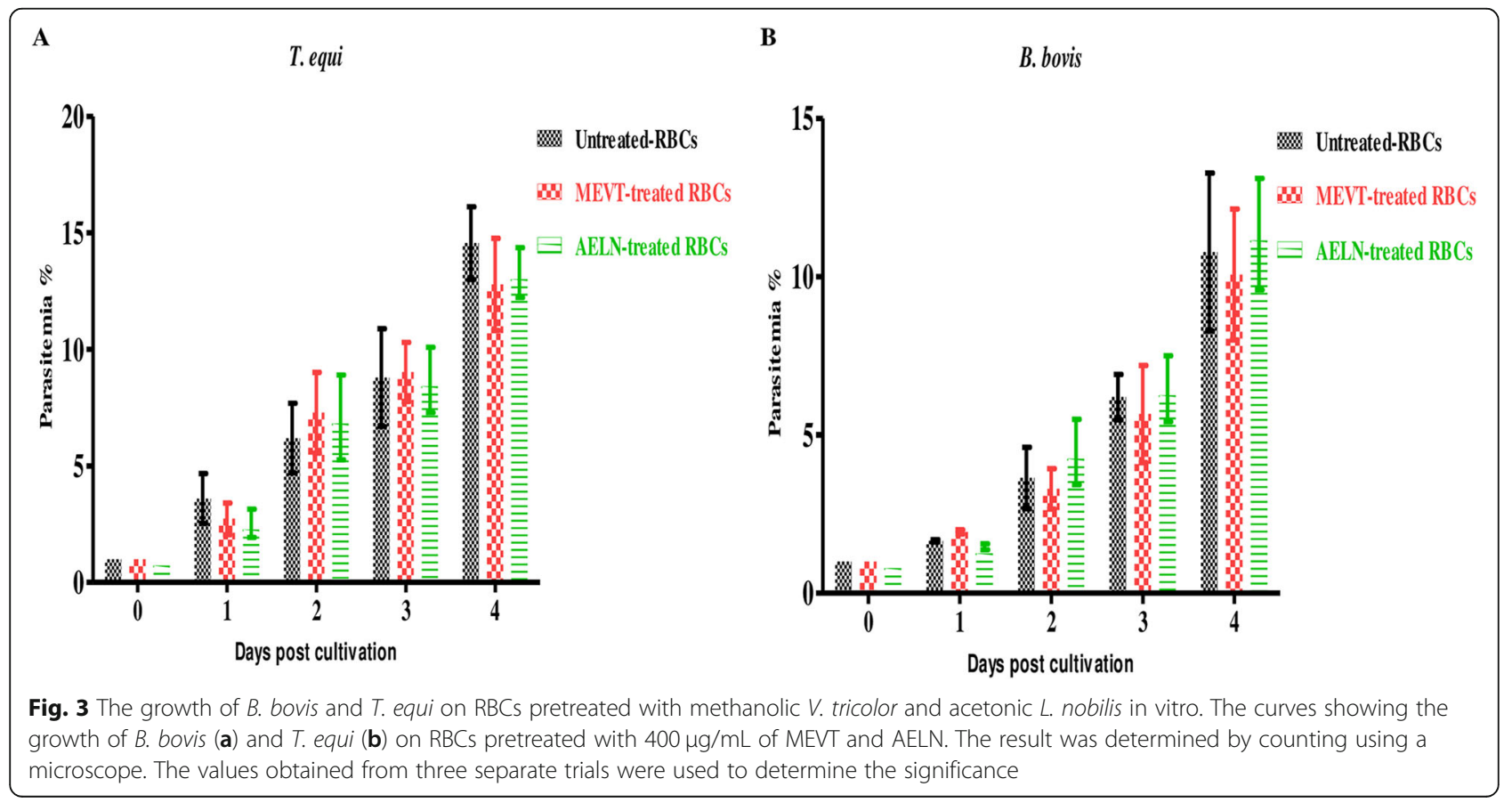


Table 2 Phytochemical screening of methanolic Viola tricolor and acetonic Laurus nobilis extracts

\begin{tabular}{|c|c|c|c|c|}
\hline \multirow[t]{2}{*}{ Extracts } & \multicolumn{4}{|c|}{ Qualitative tests } \\
\hline & Tannin & Saponin & Alkaloids & Terpenoid \\
\hline Methanolic Viola tricolor & + & + & + & + \\
\hline Acetonic Laurus nobilis & + & + & + & + \\
\hline
\end{tabular}

Results expressed as the mean values from three separate trials $\pm S D$, $+=$ Positive,$-=$ Negative

\section{Results}

\section{Plant extraction}

The yield percentage of the MEVT and AELN were 7.09 and $7.25 \% \mathrm{w} / \mathrm{w}$ dry matter and dark in color.

\section{The inhibition assay of MEVT and AELN in vitro}

MEVT (Fig. 1) and AELN (Fig. 2) significantly restricted $(p<0.05)$ T. equi, B. divergens, B. caballi, B. bovis, and B. bigemina multiplication in a dose-related manner. MEVT and AELN suppressed T. equi, B. divergens, B. caballi, B. bigemina, and $B$. bovis multiplication at $\mathrm{IC}_{50}$ values shown in Table 1. For the reference antibabesial drugs, DMA and ATV suppressed T. equi, B. divergens, B. caballi, B. bigemina, and $B$. bovis multiplication at $\mathrm{IC}_{50}$ values shown in Additional file 1: Table S1. The preparatory assessment of MEVT and AELN was carried out to detect their effect on the cattle and horse RBCs. The parasite proliferation did not show a significant difference between RBCs treated with MEVT or AELN and the untreated one for B. bovis and T. equi (Fig. 3a and b).

\section{Phytochemical evaluation of MEVT and AELN extracts}

The primary examination of MEVT and AELN pointed to the existence of different phytoconstituents such as tannins, saponins, terpenoids and alkaloids that may be the main cause of their pharmaceutical properties (Table 2).

\section{Establishment of total phenolic and flavonoid contents in MEVT and AELN}

Considerable amounts of phenolic and flavonoid contents were observed in MEVT and AELN. Notably, AELN $(71.2 \pm 2.5 \mathrm{mg}$ of $\mathrm{GAE} / \mathrm{g} \mathrm{DW})$ showed the highest total phenolic content followed by MEVT $(66.5 \pm 2.9 \mathrm{mg}$ of GAE/g DW) (Table 3). Moreover, AELN (33. $8 \pm 9.7 \mathrm{mg}$ of $\mathrm{CAE} / \mathrm{g} \mathrm{DW})$ had the highest total flavonoid content followed by MEVT (39.2 $\pm 7.4 \mathrm{mg}$ of CAE/g DW) (Table 3).
Gas chromatography-mass spectrometry (GC-MS) analysis The GC-MS analysis of MEVT and AELN revealed the existence of 27 and 20 phytochemical compounds, respectively. The identified chemical composition of MEVT is shown in Table 4 and represented 29 compounds. While the identified chemical composition of AELN is shown in Table 5 and represented 24 compounds. The phytochemical compounds' identification was established on the basis of the peak area, and retention time. The active principles with their retention time (RT) and percentage of peak area (\%) are expressed in Fig. $4 \mathrm{a}$ and $\mathrm{b}$.

\section{Viability assay}

The viability test revealed that MEVT at $4 \times \mathrm{IC}_{50}(173.2$ and $192 \mu \mathrm{g} / \mathrm{mL}$ ) completely suppressed B. bigemina and B. caballi, respectively, while $6 \times \mathrm{IC}_{50}$ (324, 405.6 and $454.2 \mu \mathrm{g} / \mathrm{mL}$ ) concentration cleared $T$. equi, B. divergens and $B$. bovis, respectively (Table 4). AELN-treated $B$. bigemina, $B$. divergens, $T$. equi, and $B$. bovis completely suppressed at $6 \times \mathrm{IC}_{50}(199.8,373.2,493.2$ and $519.6 \mu \mathrm{g} /$ $\mathrm{mL}$ ), respectively except $B$. caballi completely cleared at $2 \times \mathrm{IC}_{50}(69 \mu \mathrm{g} / \mathrm{mL})$ concentration (Table 6).

\section{Toxicity activities of MEVT and AELN}

The toxicity assay of MEVT and AELN revealed that MEVT and AELN affected MDBK and NIH/3 T3 cell viability at $\mathrm{EC}_{50}$ of $930 \pm 29.9,1260 \pm 18.9$ and $573.7 \pm$ $12.4,831 \pm 19.9 \mu \mathrm{g} / \mathrm{mL}$, respectively. While HFF cell viability was not affected by the two extracts even at the highest concentration used at $1500 \mu \mathrm{g} / \mathrm{mL}$. The highest selectivity index (ratio of the effective concentration of the two extracts on the cell cultures to their inhibition concentration on the parasites) of MEVT was achieved on $B$. bigemina and found to be 21.5, 29.1 and $>34.6$ times toward MDBK, NIH/3 T3, and HFF cells, respectively, while the lowest was achieved on $B$. bovis and found to be 12.3, 16.7 and > 19.8 times toward MDBK, NIH/3 T3, and HFF cells, respectively. For AELN, the highest selectivity index was 17.2, 25 and > 45.1 times toward B. bigemina versus MDBK, NIH/3 T3, and HFF cells, respectively, while the lowest were 6.6, 9.6 and > 17.3 toward $B$. bovis versus MDBK, NIH/3 T3, and HFF cells, respectively (Table 1 ).

Table 3 Determination of total phenolic and flavonoid content of methanolic Viola tricolor and acetonic Laurus nobilis extracts

\begin{tabular}{lll}
\hline Extracts & Quantitative tests & \\
\cline { 2 - 3 } & Flavonoid mg CAE/g DW & Phenolic mg GAE/g DW \\
\hline Methanolic Viola tricolor & $33.8 \pm 9.7$ & $66.5 \pm 2.9$ \\
Acetonic Laurus nobilis & $39.2 \pm 7.4$ & $71.2 \pm 2.5$
\end{tabular}

Results expressed as the mean values from three separate trials $\pm \mathrm{SD}, \mathrm{mg} \mathrm{GAE} / \mathrm{g} \mathrm{DW}=$ gallic acid equivalents per gram of dry weight of extract, $\mathrm{mg} C A E / g$ DW $=$ catechin equivalents per gram of dry weight of extract 
Table 4 The chemical composition of MEVT by GC-MS

\begin{tabular}{|c|c|c|c|c|c|}
\hline Peak & R.t $\mathrm{t}^{\mathrm{a}}$ & Name & Area \% & Molecular Weight & Molecular formula \\
\hline 1 & 4.93 & Methanesulfonylacetic acid & 1.99 & 138 & $\mathrm{C}_{3} \mathrm{H}_{6} \mathrm{O}_{4} \mathrm{~S}$ \\
\hline 2 & 6.62 & (+)-Sabinene & 1.34 & 136 & $\mathrm{C}_{10} \mathrm{H}_{16}$ \\
\hline 3 & 7.03 & Eucalyptol & 10.35 & 154 & $\mathrm{C}_{10} \mathrm{H}_{18} \mathrm{O}$ \\
\hline 4 & 8.82 & Undecane & 7.36 & 156 & $\mathrm{C}_{11} \mathrm{H}_{24}$ \\
\hline 5 & 11.33 & L-à-Terpineol & 1.42 & 154 & $\mathrm{C}_{10} \mathrm{H}_{18} \mathrm{O}$ \\
\hline 6 & 12.09 & Cinnamic acid, linalyl ester & 0.74 & 284 & $\mathrm{C}_{19} \mathrm{H}_{24} \mathrm{O}_{2}$ \\
\hline 7 & 12.64 & Benzaldehyde, 4-(1-methylethyl)- & 1.10 & 148 & $\mathrm{C}_{10} \mathrm{H}_{12} \mathrm{O}$ \\
\hline 8 & 12.76 & (-)-Carvone & 0.80 & 150 & $\mathrm{C}_{10} \mathrm{H}_{14} \mathrm{O}$ \\
\hline 9 & 13.46 & Cinnamaldehyde, (E)- & 20.23 & 132 & $\mathrm{C}_{9} \mathrm{H}_{8} \mathrm{O}$ \\
\hline 10 & 13.89 & Anethole & 1.30 & 148 & $\mathrm{C}_{10} \mathrm{H}_{12} \mathrm{O}$ \\
\hline 11 & 15.59 & à-Terpinyl acetate & 5.47 & 196 & $\mathrm{C}_{12} \mathrm{H}_{20} \mathrm{O}_{2}$ \\
\hline 12 & 15.72 & Benzene, 1-Methoxy-2-nitro- & 2.74 & 152 & $\mathrm{C}_{7} \mathrm{H}_{7} \mathrm{NO}_{3}$ \\
\hline 13 & 16.27 & Copaene & 2 & 204 & $\mathrm{C}_{15} \mathrm{H}_{24}$ \\
\hline 14 & 16.70 & ç-Elemene & 0.66 & 204 & $\mathrm{C}_{15} \mathrm{H}_{24}$ \\
\hline 15 & 17.06 & Methyleugenol & 0.58 & 178 & $\mathrm{C}_{11} \mathrm{H}_{14} \mathrm{O}_{2}$ \\
\hline 16 & 17.38 & Caryophyllene & 0.80 & 204 & $\mathrm{C}_{15} \mathrm{H}_{24}$ \\
\hline 17 & 18.29 & 1,2-Benzenedicarboxylic acid, dimethyl ester & 1.40 & 194 & $\mathrm{C}_{10} \mathrm{H}_{10} \mathrm{O}_{4}$ \\
\hline 18 & 19.44 & à-Muurolene & 1.19 & 204 & $\mathrm{C}_{15} \mathrm{H}_{24}$ \\
\hline 19 & 20.00 & Cadina-1(10),4-diene & 1.96 & 204 & $\mathrm{C}_{15} \mathrm{H}_{24}$ \\
\hline 20 & 25.09 & 2H-Pyran-3-ol, tetrahydro-2,2,6-trimethyl-6-(4-methyl-3-cyclohexen-1-yl)-, [3S-[3à,6à( $\left.\left.R^{a}\right)\right]$ - & 2.45 & 238 & $\mathrm{C}_{15} \mathrm{H}_{26} \mathrm{O}_{2}$ \\
\hline 21 & 26.85 & Isopropyl myristate & 2.92 & 270 & $\mathrm{C}_{17} \mathrm{H}_{34} \mathrm{O}_{2}$ \\
\hline 22 & 27.09 & Neophytadiene & 5.94 & 278 & $\mathrm{C}_{20} \mathrm{H}_{38}$ \\
\hline 23 & 27.21 & 2-Pentadecanone, 6,10,14-trimethyl- & 1.07 & 268 & $\mathrm{C}_{18} \mathrm{H}_{36} \mathrm{O}$ \\
\hline 24 & 28.88 & Hexadecanoic acid, methyl ester & 4.16 & 270 & $\mathrm{C}_{17} \mathrm{H}_{34} \mathrm{O}_{2}$ \\
\hline 25 & 32.09 & 12,15-Octadecadienoic acid, methyl ester & 1.50 & 294 & $\mathrm{C}_{19} \mathrm{H}_{34} \mathrm{O}_{2}$ \\
\hline 26 & 32.21 & 1-Hexadecanol, 2-methyl- & 9.94 & 256 & $\mathrm{C}_{17} \mathrm{H}_{36} \mathrm{O}$ \\
\hline 27 & 32.44 & Phytol & 0.95 & 296 & $\mathrm{C}_{20} \mathrm{H}_{40} \mathrm{O}$ \\
\hline 28 & 32.71 & Heptadecanoic acid, 9-methyl-, methyl ester & 1.12 & 298 & $\mathrm{C}_{19} \mathrm{H}_{38} \mathrm{O}_{2}$ \\
\hline 29 & 35.74 & Docosane & 6.11 & 310 & $\mathrm{C}_{22} \mathrm{H}_{46}$ \\
\hline
\end{tabular}

${ }^{\mathrm{a}}$ R.t, retention time $(\mathrm{min})$

\section{Combination treatment in vitro}

The MEVT/DMA combined treatment was additive toward T. equi, B. divergens, B. bovis and B. caballi, while showed an antagonistic efficacy toward B. bigemina. AELN/DMA combined treatment was antagonistic toward $T$. equi, $B$. divergens, $B$. bigemina, and $B$. bovis, while was additive toward B. caballi (Table 7). The combination effects of MEVT and AELN with ATV were shown in Table 5.

\section{The in vivo chemotherapeutic potential of MEVT and}

\section{AELN in mice}

To investigate the chemotherapeutic potential of MEVT and AELN in vivo, six-female $\mathrm{BALB} / \mathrm{c}$ mice were infected by $B$. microti and the two extracts were administered for 5 days after the infection reach $1 \%$ parasitemia.
On eighth day post-infection (p.i), the control group treated with double distillate water (DDW) exhibited rapid growth of parasitemia reached $58.2 \%$ and the parasitemia reduced slowly on the subsequent days. The level of parasitemia in all treated groups reached 37.8, 25.5 and $3.9 \%$ in MEVT (150 $\left.\mathrm{mg} \mathrm{kg}^{-1}\right)$, AELN (150 $\mathrm{mg} \mathrm{kg}^{-1}$ ), and DMA (25 $\mathrm{mg} \mathrm{kg}^{-1}$ ), respectively, at 8 days p.i (Fig. 5). Additionally, the hematology parameters; HCT percentage, RBCs count and HGB concentration (Fig. 6a-c) showed a significant difference in the MEVT- and AELN-treated groups when compared with the positive control group. Whereas, the comparison of the hematology parameters during in vivo studies showed no significant difference $(p<0.05)$ between MEVT-, AELN-treated groups as compared to the DMA-treated group. 
Table 5 The chemical composition of AELN by GC-MS

\begin{tabular}{|c|c|c|c|c|c|}
\hline Peak & $\mathrm{R}_{\mathrm{t}}^{\mathrm{a}}$ & Name & Area \% & Molecular Weight & Molecular formula \\
\hline 1 & 4.49 & Cumene & 3.19 & 120 & $\mathrm{C}_{9} \mathrm{H}_{12}$ \\
\hline 2 & 4.67 & à-Pinene & 1.12 & 136 & $\mathrm{C}_{10} \mathrm{H}_{16}$ \\
\hline 3 & 5.54 & (+)-Sabinene & 3.46 & 136 & $\mathrm{C}_{10} \mathrm{H}_{16}$ \\
\hline 4 & 6.94 & Eucalyptol & 21.68 & 154 & $\mathrm{C}_{10} \mathrm{H}_{18} \mathrm{O}$ \\
\hline 5 & 8.81 & 3,7-Dimethylocta-1,6-dien-3-ol & 1.05 & 154 & $\mathrm{C}_{10} \mathrm{H}_{18} \mathrm{O}$ \\
\hline 6 & 11.30 & Beta-fenchol & 3.22 & 154 & $\mathrm{C}_{10} \mathrm{H}_{18} \mathrm{O}$ \\
\hline 7 & 12.07 & Terpineol & 1.75 & 154 & $\mathrm{C}_{10} \mathrm{H}_{18} \mathrm{O}$ \\
\hline 8 & 12.74 & Carvone & 0.86 & 150 & $\mathrm{C}_{10} \mathrm{H}_{14} \mathrm{O}$ \\
\hline 9 & 15.60 & Terpinyl acetate & 20.21 & 196 & $\mathrm{C}_{12} \mathrm{H}_{20} \mathrm{O}_{2}$ \\
\hline 10 & 15.81 & Eugenol & 1.60 & 164 & $\mathrm{C}_{10} \mathrm{H}_{12} \mathrm{O}_{2}$ \\
\hline 11 & 17.06 & Methyleugenol & 1.70 & 178 & $\mathrm{C}_{11} \mathrm{H}_{14} \mathrm{O}_{2}$ \\
\hline 12 & 17.39 & Caryophyllene & 0.95 & 204 & $\mathrm{C}_{15} \mathrm{H}_{24}$ \\
\hline 13 & 19.54 & Germacra-1(10),4(15),5-triene & 1.82 & 204 & $\mathrm{C}_{15} \mathrm{H}_{24}$ \\
\hline 14 & 20.48 & cis-à-Bisabolene & 0.79 & 204 & $\mathrm{C}_{15} \mathrm{H}_{24}$ \\
\hline 15 & 21.29 & (-)-Spathulenol & 0.70 & 220 & $\mathrm{C}_{15} \mathrm{H}_{24} \mathrm{O}$ \\
\hline 16 & 21.41 & Caryophyllene oxide & 0.56 & 220 & $\mathrm{C}_{15} \mathrm{H}_{24} \mathrm{O}$ \\
\hline 17 & 22.97 & Eudesm-4(14)-en-11-ol & 0.81 & 222 & $\mathrm{C}_{15} \mathrm{H}_{26} \mathrm{O}$ \\
\hline 18 & 26.93 & $\begin{array}{l}\text { 2(3H)-Benzofuranone, 6-ethenylhexahydro-6-methyl- } \\
\text { 3-methylene-7-(1-methylethenyl)-, [3aS (3aà,6à,7á,7aá)]- }\end{array}$ & 13.87 & 232 & $\mathrm{C}_{15} \mathrm{H}_{20} \mathrm{O}_{2}$ \\
\hline 19 & 27.67 & Gazaniolide & 7.56 & 230 & $\mathrm{C}_{15} \mathrm{H}_{18} \mathrm{O}$ \\
\hline 20 & 29.67 & Spirafolide & 2.30 & 246 & $\mathrm{C}_{15} \mathrm{H}_{18} \mathrm{O}_{3}$ \\
\hline 21 & 30.11 & Dehydrocostuslactone & 3.28 & 230 & $\mathrm{C}_{15} \mathrm{H}_{18} \mathrm{O}_{2}$ \\
\hline 22 & 30.33 & Eremanthin & 2.01 & 230 & $\mathrm{C}_{15} \mathrm{H}_{18} \mathrm{O}_{2}$ \\
\hline 23 & 31.61 & Costunolide & 2.99 & 232 & $\mathrm{C}_{15} \mathrm{H}_{20} \mathrm{O}_{2}$ \\
\hline 24 & 32.44 & Phytol & 1.29 & 296 & $\mathrm{C}_{20} \mathrm{H}_{40} \mathrm{O}$ \\
\hline
\end{tabular}

${ }^{\mathrm{a}}$ R.t, retention time $(\mathrm{min})$

\section{Discussion}

Plant extracts possess significant therapeutic effects with minimal side effects for the treatment of many infectious diseases [33], thus making medicinal plants an attractive choice for the source of new therapeutic compounds [34]. In spite of the antiparasitic effect of $V$. tricolor and L. nobilis, they have not been evaluated against piroplasmosis. Therefore, this study investigates the in vitro as well as in vivo antipiroplasmic efficacy of MEVT and AELN.

The existing study revealed that MEVT and AELN possess various biologically active compounds and the primary screening emphasized that both extracts contain terpenoids, alkaloids, flavonoids, and tannins (Table 2). The qualitative examination revealed the presence of significant amounts of polyphenols and flavonoids (Table $3)$. Notably, this finding conforms to the report by Chandra et al. [42] and Alejo-Armijo et al. [43] who revealed the existence of these active constituents in both extracts. It has been shown that all these secondary metabolites have many therapeutic properties and are known to be pharmacologically active components.

The phytochemical constituents of MEVT and AELN were detected using GC-MS analyses. The analysis revealed that MEVT consisted of 29 compounds and the main chemical components identified were cinnamaldehyde, (E) - (20.23\%), eucalyptol (10.35\%), 1-hexadecanol, 2-methyl- (9.94\%), undecane (7.36\%), docosane (6.11\%), Cadina-1(10), neophytadiene (5.94\%) and à-terpinyl acetate $(5.47 \%)$. While AELN was found to possess 24 compounds and the main chemical components identified were eucalyptol (21.68\%), terpinyl acetate (20.21\%), 2(3H)benzofuranone, 6-ethenylhexahydro-6-methyl-3-methylene-7-(1-methylethenyl)-, [3aS (3aà,6à,7á,7aá)] (13.87\%), and gazaniolide $(7.56 \%)$. Some of our GC-MS results were consistent with previous reports [25, 26, 44], however, the difference in some compounds may be attributed to the type of solvents used and the extraction method.

The in vitro experiments indicated that MEVT and AELN suppressed the in vitro multiplication of piroplasm parasites. Previous reports documented that $V$. 


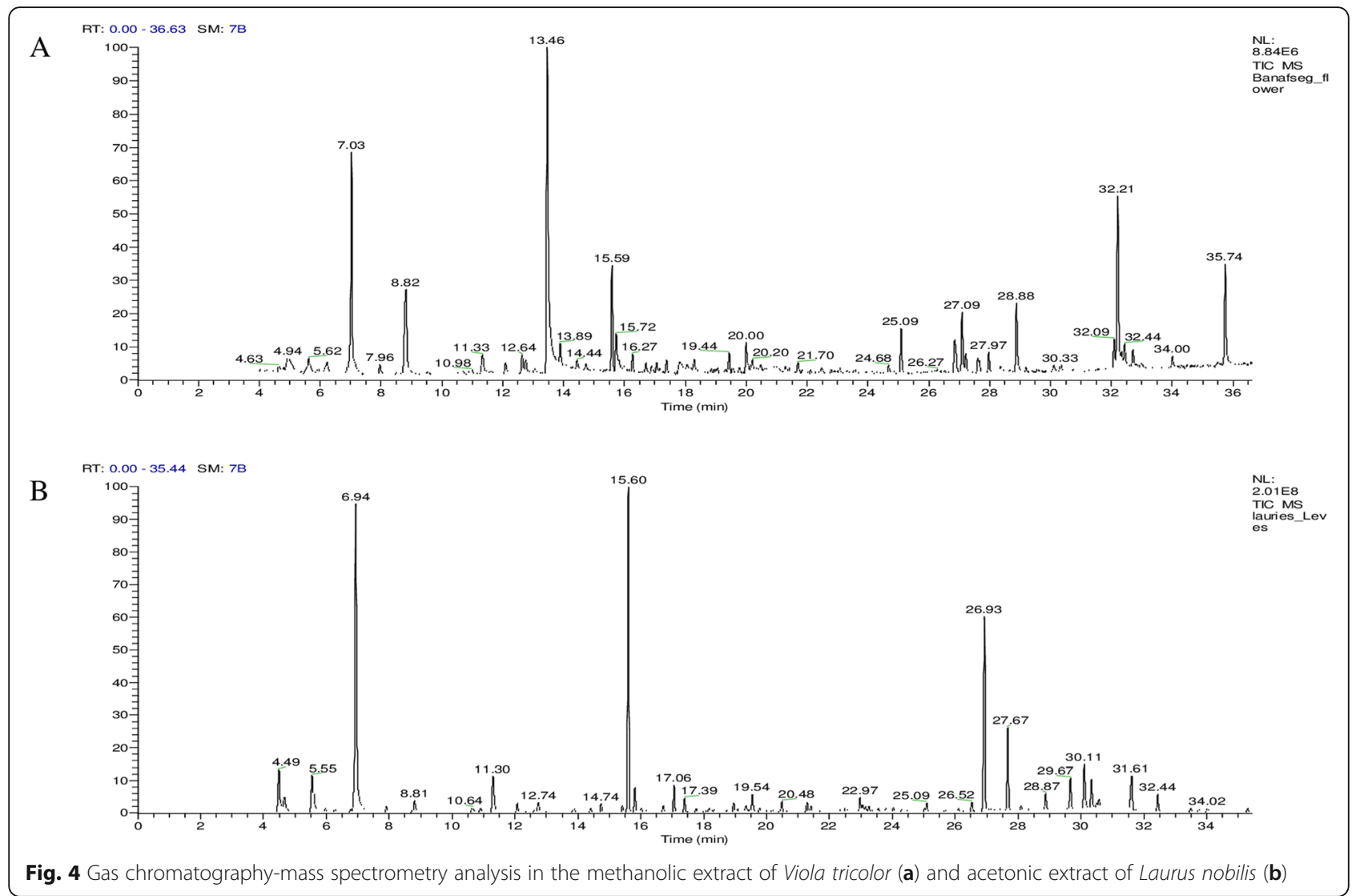

tricolor and L. nobilis herbal extracts have potent efficacy toward Plasmodium, Trypanosoma, and Leishmania [5, 21]. For instance, Dua et al. [5] exhibited the antiplasmodial activity of petroleum ether extract of Viola canescens with an $\mathrm{IC}_{50}$ equal to $2.76 \mu \mathrm{g} / \mathrm{mL}$, as well as its efficacy toward Leishmania donovani and Trypanosoma cruzi with $\mathrm{IC}_{50}$ values of $0.40 \mu \mathrm{g} / \mathrm{mL}$ and $1.86 \mu \mathrm{g} / \mathrm{mL}$, respectively. In addition to antiprotozoal effectiveness $V$. tricolor and $L$. nobilis extracts, Ozcan et al. [6] and Koike et al. [14] reported that L. nobilis

Table 6 Viability of parasites treated with MEVT and AELN

\begin{tabular}{|c|c|c|c|c|c|c|}
\hline \multirow[t]{2}{*}{ Extracts } & \multirow[t]{2}{*}{ Conc. } & \multicolumn{5}{|l|}{ Parasites } \\
\hline & & B. bovis & B. bigemina & B. divergens & B. caballi & T. equi \\
\hline \multirow[t]{6}{*}{ MEVT } & $0.25 \times I C_{50}$ & + & + & + & + & + \\
\hline & $0.5 \times \mathrm{IC}_{50}$ & + & + & + & + & + \\
\hline & $1 \times I C_{50}$ & + & + & + & + & + \\
\hline & $2 \times I_{50}$ & + & + & + & + & + \\
\hline & $4 \times I C_{50}$ & + & - & + & - & + \\
\hline & $6 \times I_{50}$ & - & - & - & - & - \\
\hline \multirow[t]{7}{*}{ AELN } & $0.25 \times I C_{50}$ & + & + & + & + & + \\
\hline & $0.5 \times \mathrm{IC}_{50}$ & + & + & + & + & + \\
\hline & $1 \times I C_{50}$ & + & + & + & + & + \\
\hline & $2 \times I C_{50}$ & + & + & + & - & + \\
\hline & $4 \times I C_{50}$ & + & + & + & - & + \\
\hline & $6 \times I_{50}$ & - & - & - & - & - \\
\hline & Untreated control & + & + & + & + & + \\
\hline
\end{tabular}

Results are calculated as the mean values from three separate trials \pm SD, a positive (+) indicates parasites regrowth, and a negative (-) shows the parasites total clearance after drug pressure withdrawal using microscopy assay 
Table 7 Combination effect of MEVT and AELN with DMA and ATV

\begin{tabular}{|c|c|c|c|}
\hline Parasite & Drug combination & $\mathrm{Cl}$ value & Degree of association \\
\hline \multirow[t]{4}{*}{ B. bovis } & MEVT + DMA & 1.200 & Additive \\
\hline & AELN + DMA & 5.742 & Antagonism \\
\hline & MEVT + ATV & 0.209 & Synergism \\
\hline & AELN + ATV & 0.822 & Synergism \\
\hline \multirow[t]{4}{*}{ B. bigemina } & MEVT + DMA & 4.991 & Antagonism \\
\hline & AELN + DMA & 3.266 & Antagonism \\
\hline & MEVT + ATV & 0.273 & Synergism \\
\hline & AELN + ATV & 0.776 & Synergism \\
\hline \multirow[t]{4}{*}{ B. divergens } & MEVT + DMA & 1.072 & Additive \\
\hline & AELN + DMA & 8.667 & Antagonism \\
\hline & MEVT + ATV & 0.304 & Synergism \\
\hline & AELN + ATV & 1.003 & Additive \\
\hline \multirow[t]{4}{*}{ B. caballi } & MEVT + DMA & 0.989 & Additive \\
\hline & AELN + DMA & 0.947 & Additive \\
\hline & MEVT + ATV & 0.291 & Synergism \\
\hline & AELN + ATV & 0.392 & Synergism \\
\hline \multirow[t]{4}{*}{ T. equi } & MEVT + DMA & 0.893 & Additive \\
\hline & AELN + DMA & 8.965 & Antagonism \\
\hline & MEVT + ATV & 0.844 & Synergism \\
\hline & AELN + ATV & 0.999 & Additive \\
\hline
\end{tabular}

MEVT methanolic extract of $V$. tricolor, AELN acetonic extract of L. nobilis, DMA diminazene aceturate, $A T V$ atovaquone. $\mathrm{Cl}$ denotes the combination index value and $V$. tricolor has strong antioxidant, antimicrobial and antibacterial activity. Interestingly, recent studies documented the antiprotozoal activities of various bioactive molecules identified in our GC-MS analysis. For instance, Castaño Osorio and Giraldo García [45]. reported that different sesquiterpene lactones and costunolide, isolated from Laurus nobilis, showed antiprotozoal efficacy against Trypanosoma brucei rhodesiense. Colares et al. [46] and Le et al. [47] proved the antileishmanial activity of eugenol and methyleugenol against promastigotes of L. amazonensis. Moreover, Charma et al. [48] documented the antileishmanial effect of cinnamaldehyde and eugenol with $\mathrm{IC}_{50}$ values of 0.681 and $1.426 \mathrm{~g} / \mathrm{ml}$, respectively. Eucalyptol and caryophyllene showed antitrypanosomal and antileishmanial activities, respectively [49]. Therefore, we hypothesized that eucalyptol, caryophyllene, cinnamaldehyde, eugenol, methyleugenol, and costunolide are the main active compounds responsible for the antipiroplasmic activity of MEVT and AELN.

The CCK test used to examine the cytotoxicity of MEVT and AELN revealed their effect on NIH/3 T3, HFFs, and MDBK cell viability with a slightly high selective index value. Meaning that MEVT and AELN are more likely to affect the viability of piroplasm parasites rather than host cells. Notably, this finding conforms to the report by Dua et al. [5], who revealed that Viola extract exhibited antiplasmodial activity with some cytotoxic efficacy toward the L-6 cell line. Furthermore, Kivçak and Mert [28]. documented the safety of water and ethanol L. nobilis extracts on the Brine shrimp. Previous reports documented the cytotoxic activities of the

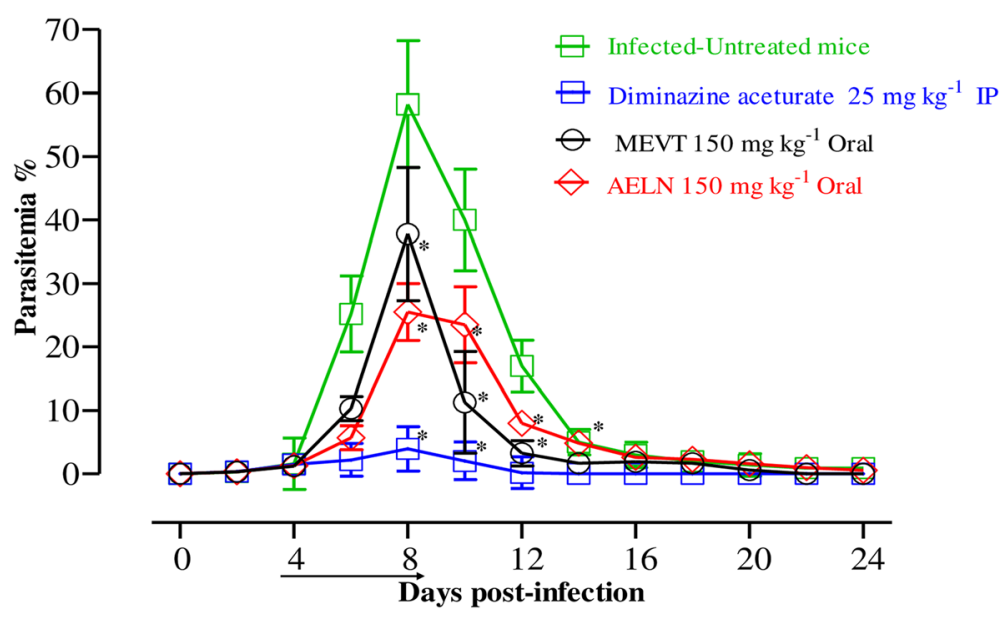

Fig. 5 The growth inhibition of methanolic $V$. tricolor and acetonic L. nobilis on B. microti in vivo. Inhibitory effect of MEVT and AELN on the growth of $B$. microti in mice, based on observations taken from five mice per experimental group. The arrow indicates 5 consecutive days of treatment. Asterisks indicate statistically significant $(p<0.05)$ differences of parasitemia between treated groups and the untreated control group based on one-way ANOVA Tukey's test using GraphPad Prism version 5.0 for Windows (GraphPad Software Inc., San Diego, CA, USA). Parasitemia was calculated by counting iRBCs among 2000 RBCs using Giemsa-stained thin blood smears. The data were the mean and standard deviation from two separate experiments 


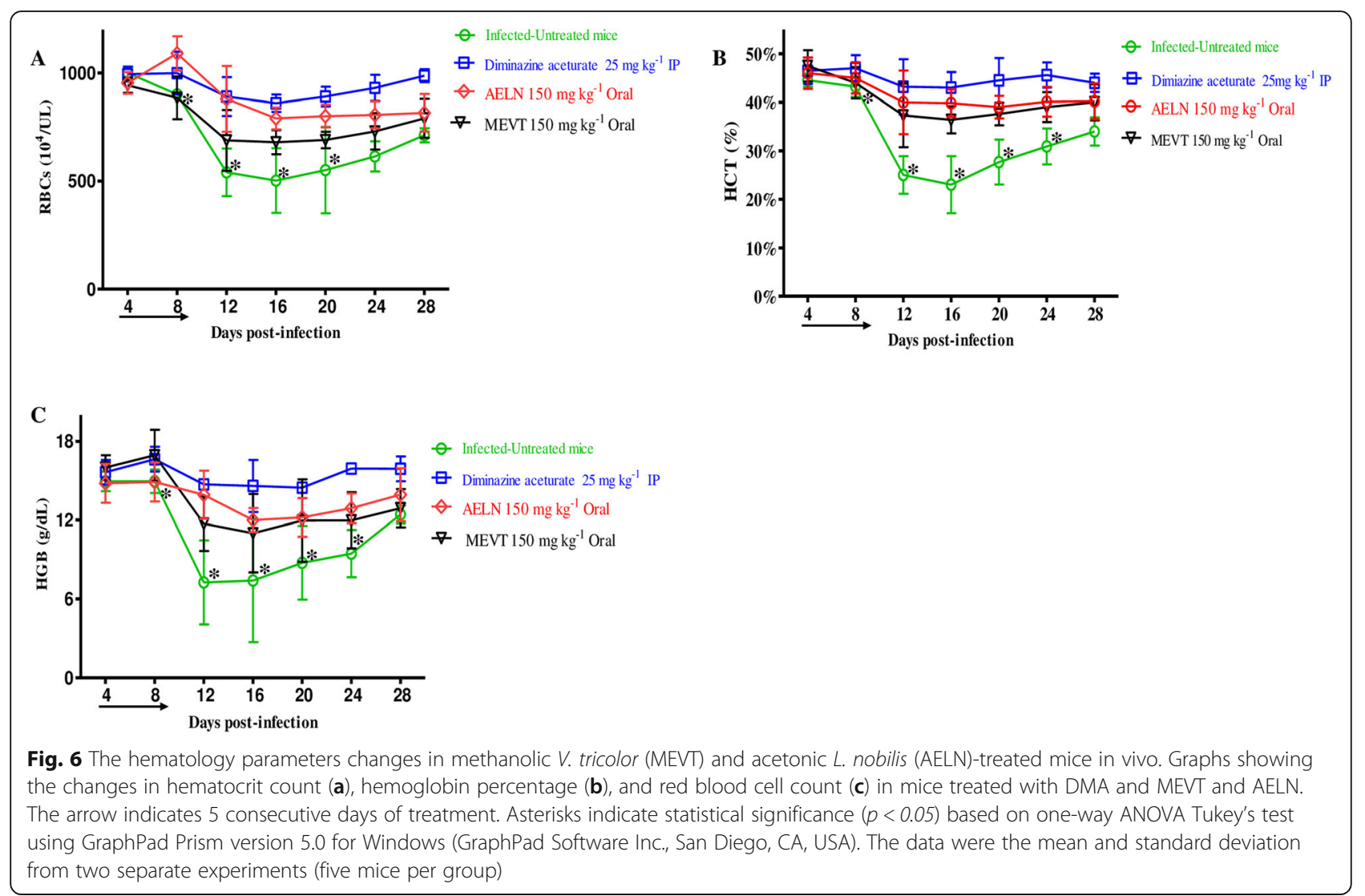

L. nobilis extracts and its main component 1,8-cineole in a human neuroblastoma cell line (SH-SY5Y), as well as, the cytotoxic activity of the $V$. tricolor extracts and its main component cyclotides were evaluated in normal cell lines. Their $\mathrm{EC}_{50}$ values were higher than $400 \mu \mathrm{g} / \mathrm{mL}$ concentration, suggesting their safety on the normal cell lines $[17,23]$.

Nowadays, combination chemotherapies are being reported to alleviate serious diseases, including pulmonary tuberculosis, malignancy, immune deficiency syndrome, and some protozoal diseases to promote higher therapeutic efficacy. The MEVT-DMA or ATV combined effects were additive toward all tested parasites. Likewise, AELN combined with DMA and ATV showed additive and synergistic effects toward T. equi, B. caballi, B. bigemina, $B$. divergens and $B$. bovis. These results are compatible with Batiha et al. [3] who previously investigated the in vitro combined efficacy of methanolic extracts of $S$. aromaticum and C. sinensis with DMA and ATV toward piroplasm parasites. They concluded that these combined effects are property for developing new chemotherapy techniques against piroplasm parasites. Together, these findings in our study emphasize that these combinations have prospects to be used as a treatment option of animal and human babesiosis.
In the in vivo experiment, the oral administration of MEVT and AELN resulted in 35.1 and $56.1 \%$ suppression in the parasitemia level on the eighth-day p.i., respectively when compared with $93.2 \%$ restriction showed by DMA. The effectiveness of MEVT and AELN was comparable to that shown by Batiha et al. [3], who reported that the methanolic extracts of $S$. aromaticum and $C$. sinensis on the eighth-day p.i. resulted in 69.2 and $42.4 \%$ inhibition in the parasitemia at day 8 p.i., respectively. Interestingly, no obvious toxic signs were observed in MEVT- and AELN-treated mice.

Nevertheless, MEVT and AELN, like DMA, prohibited anemia development in mice, although temporal reductions were observed in HCT, RBCs, and HGB. Furthermore, neither the MEVT nor the AELN treatments showed any apparent toxic symptoms or promoted anemia in uninfected mice. Interestingly, many reports have shown remarkable antioxidant and pro-oxidative effects of ethanol and water extract of the whole plant of Viola by prohibiting the reactive oxygen species (ROS) generation or stimulating the protein detoxification [11]. Additionally, Emam et al. [22] observed the significant antioxidant, antipyretic, and anti-inflammatory properties after L. nobilis extracts treatment. Moreover, Ozcan et al. [6] reported that essential oil, methanolic extract of seed oil and seed oil from $L$. nobilis possess antioxidant 
and antimicrobial activities. Such medicinal characteristics are important for piroplasmosis treatment because piroplasmosis infection is not only correlated with emaciation and poor growth performance in cattle but also with immunosuppression and overproduction of reactive oxygen and nitrogen species [3]. The limitation of this study is performing the cytotoxicity assay in vitro using cell lines, and it is recommended to evaluate the cytotoxic activity of our extracts in vivo.

These findings emphasize the MEVT and AELN ability to eradicate B. microti in mice. Taken together, these findings support that MEVT and AELN could be a potential source of alternate chemotherapy against $B$. microti infection in humans.

\section{Conclusions}

To our knowledge, this is the first antipiroplasmic evaluation of methanolic $V$. tricolor and acetonic $L$. nobilis extracts against piroplasm parasites. MEVT and AELN exhibited an in vitro growth inhibitory effect against five piroplasm species as well as chemotherapeutic efficacy toward B. microti in vivo. Furthermore, the combination treatment of our herbal extracts with DMA and ATV demonstrated synergistic and additive effectiveness against all testes parasites. Our GC-MS analysis results documented the existence of several phytochemical molecules that may be responsible for the babesicidal activities of MEVT and AELN. Therefore, it is recommended to evaluate the antipiroplasmic efficacy of the GC-MS identified compounds for the future discovery of a novel potential drug against piroplasmosis. And evaluate the actual mode of action employed against the recovery of piroplasm parasites.

\section{Supplementary information}

Supplementary information accompanies this paper at https://doi.org/10. 1186/s12906-020-2848-2.

Additional file 1: Table S1. The $I C_{50}$ and selective indexes value of ATV and DMA.

Additional file 2. ARRIVE guideline checklist.
University, Egypt for collecting and identification of plants and Dr. Sambuu Gantuya for her technical assistance.

\section{Authors' contributions}

GE-S and AM: They conceptualized, designed the study and performed the experiment. OAD, EN, LA, ER, and AEI-M: They did the statistical analysis, the results analysis, and wrote the manuscript. NY and II: They contributed critical advice and supervised the study. GE-S and AM produced the first draft, OAD, EN, ER, AEI-M, NY, and II contributed to subsequent drafts. GE-S, AM, and II led the writing process. All authors read and approved the final manuscript before submission.

\section{Funding}

This study was supported by the Ministry of Higher Education Egypt, the Japanese Society for the Promotion of Science, and the Ministry of

Education, Culture, Sports, Science and Technology, Japan (JSPS) (KAKEN Grant Number: 18H02337).

\section{Availability of data and materials}

All data generated or analyzed during this study are included in this published article [and its Additional files 1 and 2].

\section{Ethics approval and consent to participate}

The experiments described in this study were conducted according to the rules of care description and animal use in research published by Obihiro University of Agriculture and Veterinary Medicine, Japan. The protocol was approved by the Animal Experimentation Ethics committee at Obihiro University of Agriculture and Veterinary Medicine (accession number of the animal experiments: 28-111-2/28-110). These regulations were established by Fundamental Guidelines for Proper Conduct of Animal Experiment and Related Activities in Academic Research Institutions, the Ministry of Education, Culture, Sports and Technology (MEXT), Japan.

\section{Consent for publication}

Not applicable.

\section{Competing interests}

The authors declare that they have no competing interests.

\section{Author details}

${ }^{1}$ National Research Center for Protozoan Diseases, Obihiro University of Agriculture and Veterinary Medicine, Nishi 2-13, Inada-cho, Obihiro, Hokkaido 080-8555, Japan. ${ }^{2}$ Department of Pharmacology and Therapeutics, Faculty of Veterinary Medicine, Damanhour University, Damanhour, AlBeheira 22511, Egypt. ${ }^{3}$ Biology department, Faculty of Applied Sciences, Umm Al-Qura University, Makkah 21955, Saudi Arabia. ${ }^{4}$ Medicinal Biochemistry, Nanomedicine and Toxicology Laboratory, Department of Biochemistry, Landmark University, Omu-Aran, Kwara State 251101, Nigeria. ${ }^{5}$ Department of Pharmacology and Therapeutics, College of Medicine, Jouf University, Sakaka, Saudi Arabia. ${ }^{6}$ Department of Medical Pharmacology, Faculty of Medicine, Cairo University, Giza, Egypt. 'Department of Physiology, College of Medicine, Al-Azhar University, Assuit, Egypt. ${ }^{8}$ Department of Physiology, College of Medicine, Jouf University, Sakaka, Saudi Arabia. ${ }^{9}$ Department of Pharmacology, Faculty of Veterinary Medicine, Menoufia University, Shibin El Kom, Egypt.

Received: 17 December 2019 Accepted: 11 February 2020 Published online: 17 March 2020

References

1. Batiha GE-S, Beshbishy AM, Guswanto A, Nugraha AB, Munkhjargal T, AbdelDaim MM, et al. Phytochemical characterization and chemotherapeutic potential of Cinnamomum verum extracts on the multiplication of protozoan parasites in vitro and in vivo. Molecules. 2020a;25(4):996.

2. Beshbishy AM, Batiha GE, Yokoyama N, Igarashi I. Ellagic acid microspheres restrict the growth of Babesia and Theileria in vitro and Babesia microti in vivo. Parasit Vectors. 2019a;12:269.

3. Batiha GE-S, Beshbishy AA, Tayebwa DS, Shaheen MH, Yokoyama N, Igarashi I. Inhibitory effects of Syzygium aromaticum and Camellia sinensis methanolic extracts on the growth of Babesia and Theileria parasites. Ticks Tick Borne Dis. 2019b;10:949-58.

\section{Acknowledgments}

The authors would like to thank members of the Pharmacology and Chemotherapeutics Department, Faculty of Veterinary Medicine, Damanhour

AELN: Acetonic extract of L. nobilis; ATV: Atovaquone; CCK-8: Cell Counting aceturate; DMEM: Dulbecco's Modified Eagle's Medium; DMSO: Dimethyl bovine kidney; MEM: Minimum Essential Medium Eagle; MEVT: Methanolic extract of V. tricolor; NIH/3 T3: Mouse embryonic fibroblast; RBCs: Red blood cells
\end{abstract}


4. Batiha GE-S, Beshbishy AM, Adeyemi OS, Nadwa E, Rashwan E, Yokoyama N, et al. Safety and efficacy of hydroxyurea and eflornithine against most blood parasites Babesia and Theileria. PLoS ONE. 2020b;15(2):e0228996.

5. Dua VK, Verma G, Agarwal D, Kaiser DM, Brun R. Antiprotozoal activities of traditional medicinal plants from the Garhwal region of northwest Himalaya. India J Ethnopharm. 2011;136:123-8.

6. Ozcan B, Esen M, Sangun MK, Coleri A, Caliskan M. Effective antibacterial and antioxidant properties of methanolic extract of Laurus nobilis seed oil. J Environ Biol. 2010;31:637-41.

7. Patrakar R, Mansuriya M, Patil P. Phytochemical and pharmacological review on Laurus nobilis. Int J Pharm Chem Sci. 2012;1:595-602.

8. Feyzabadi Z, Ghorbani F, Vazani Y, Zarshenas MM. A critical review on phytochemistry, pharmacology of Viola odorata L. and related multipotential products in traditional Persian medicine. Phytother Res. 2017; 31:1669-75.

9. Hellinger R, Koehbach J, Fedchuk H, Sauer B, Huber R, Gruber CW, et al. Immunosuppressive activity of an aqueous Viola tricolor herbal extract. J Ethnopharmacol. 2014;151:299-306

10. Witkowska-Banaszczak E, Bylka W, Matlawska I, Goslinska O, Muszynski Z Antimicrobial activity of Viola tricolor herb. Fitoterapia. 2005;76:458-61.

11. Bachheti RK, Yousuf S, Sharama RG, Joshi A, Mathur A. Screening of Viola patrinii for antioxidant potential and presence of phytochemicals. Int J Chem Tech Res. 2014;6:2316-22.

12. Goransson U, Svangard E, Claeson P, Bohlin L. Novel strategies for isolation and characterization of cyclotides: the discovery of bioactive macrocyclic plant polypeptides in the Violaceae. Curr Protein Pept Sci. 2004;5:317-29.

13. Chen B, Colgrave ML, Daly NL, Rosengren KJ, Gustafson KR, Craik DJ. Isolation and characterization of novel cyclotides from Viola hederaceae: solution structure and anti-HIV activity of vhl-1, a leaf-specific expressed cyclotide. J Biol Chem. 2005;280:22395-405.

14. Koike A, Barreira JCM, Barros L, Santos-Buelga C, Villavicencio ALCH, Ferreira ICFR. Edible flowers of Viola tricolor $L$. as a new functional food: antioxidant activity, individual phenolics and effects of gamma and electron-beam irradiation. Food Chem. 2015;179:6-14.

15. Toiu A, Vlase L, Oniga I, Tamas M. Quantitative analysis of some phenolic compounds from Viola species tinctures. Farmacia J. 2008:56:440-5.

16. Anca T, Philippe V, llioara $O$, Mircea T. Composition of essential oils of Viola tricolor and V. arvensis from Romania. Chem Nat Comp. 2009:45:91-2.

17. Svangard E, Goransson U, Hocaoglu Z, Gullbo J, Larsson R, Claeson P, et al. Cytotoxic cyclotides from Viola tricolor. J Nat Prod. 2004;67:144-7.

18. Toiu A, Parvu AE, Oniga I, Tamas M. Evaluation of anti-inflammatory activity of alcoholic extract from Viola tricolor. Rev Med Chir Soc Med Nat lasi. 2007; 111:525-9.

19. Porrini MP, Fernández NJ, Garrido PM, Gende LB, Medici SK, Equaras MJ. In vivo evaluation of antiparasitic activity of plant extracts on nosema ceranae (microsporidia). Apidologie. 2011;42(6):700-7.

20. Piana M, Silva MA, Trevisan G, de Brum TF, Silva CR, Boligon AA, et al. Antiinflammatory effects of Viola tricolor gel in a model of sunburn in rats and the gel stability study. J Ethnopharmacol. 2013;150(2):458-65.

21. Moon H-I, Jung J-C, Lee J. Antiplasmodial activity of triterpenoid isolated from whole plants of Viola genus from South Korea. Parasitol Res. 2006;100: 641-4.

22. Emam AM, Mohamed MA, Diab YM, Megally NY, Mohamed DY. Isolation and structure elucidation of antioxidant compounds from leaves of Laurus nobilis and Emex spinosus. Drug Discov Ther. 2010;4:202-7.

23. Pacifico S, Gallicchio M, Lorenz P, Potenza N, Galasso S, Marciano S, et al. Apolar Laurus nobilis leaf extracts induce cytotoxicity and apoptosis towards three nervous system cell lines. Food Chem Toxicol. 2013;62:628-37.

24. Bouzouita N, El Omri A, Kachouri F, Wathelet J, Marlier M, Chaabouni MM. Chemical composition and antioxidant activity of Laurus nobilis floral buds essential oil. J Essent Oil Bear PI. 2009;12(6):694-702.

25. Santos FA, Rao VS. Antiinflammatory and antinociceptive effects of 1,8cineole a terpenoid oxide present in many plant essential oils. Phytother Res. 2000;14:240-4.

26. Braun NA, Meier M, Kohlenberg B, Hammerschmidt FJ. $\delta$-Terpinyl acetate: a new natural component from the essential leaf oil of Laurus nobilis $\mathrm{L}$. (Lauraceae). J Essent Oil Res. 2001;13:95-7.

27. Abu-Dahab R, Kasabri V, Afifi FU. Evaluation of the volatile oil composition and antiproliferative activity of Laurus nobilis L. (Lauraceae) on breast cancer cell line models. Rec Nat Prod. 2014;8:136-47.
28. Kivçak B, Mert T. Preliminary evaluation of cytotoxic properties of Laurus nobilis leaf extracts. Fitoterapia. 2002;73:242-3.

29. Derwich H, Benziane Z, Boukir A. Chemical composition and antibacterial activity of leaves essential oil of Laurus nobilis from Morocco. Aust J Basic \& Appl Sci. 2009;3(4):3818-24.

30. Kaurinovic B, Popovic M, Vlaisavljevic S. In vitro and in vivo effects of Laurus nobilis L. leaf extracts. Molecules. 2010;15(5):3378-90.

31. Fidan H, Stefanova G, Kostova I, Stankov S, Damyanova S, Stoyanova A, Zheljazkov VD. Chemical composition and antimicrobial activity of Laurus nobilis L. Essential oils from Bulgaria. Molecules. 2019;24(4):804.

32. Basak SS, Candan F. Effect of Laurus nobilis L. essential oil and its main components on a-glucosidase and reactive oxygen species scavenging activity. Iran J Pharm Res. 2013;12(2):367-79.

33. Beshbishy AM, Batiha GE-S, Adeyemi OS, Yokoyama N, Igarashi I. Inhibitory effects of methanolic Olea europaea and acetonic Acacia laeta on the growth of Babesia and Theileria. Asian Pac J Trop Med. 2019b;12:425-34.

34. Batiha GE-S, Beshbishy AA, Tayebwa DS, Shaheen MH, Yokoyama N, Igarashi I. Inhibitory effects of Uncaria tomentosa bark, Myrtus communis roots, Origanum vulgare leaves and Cuminum cyminum seeds extracts against the growth of Babesia and Theileria in vitro. Jap J Vet Parasitol. 2018;17:1-13.

35. Hamdy E. Trease and Evans pharmacognosy SIXTEENTH EDITION. Trease and Evans pharmacognosy; 2009

36. Jhaumeer Laulloo S, Bhowon MG, Soyfoo S, Chua LS. Nutritional and biological evaluation of leaves of Mangifera indica from Mauritius. J Chem. 2018;2018:6869294.

37. Zhishen J, Mengcheng T, Jianming $W$. The determination of flavonoid contents in mulberry and their scavenging effects on superoxide radicals. Food Chem. 1999;64:555-9.

38. Ma XK, Li XF, Zhang JY, Lei J, Li WW, Wang G. Analysis of the volatile components in Selaginella doederleinii by headspace solid phase micro extraction-gas chromatography-mass spectrometry. Molecules. 2019;25(1):E115.

39. Batiha GE-S, Beshbishy AM, Adeyemi OS, Nadwa EH, Rashwan EM, Alkazmi $L M$, Elkelish AA, Igarashi I. Phytochemical screening and antiprotozoal effects of the methanolic Berberis vulgaris and acetonic Rhus coriaria extracts. Molecules. 2020;25:550.

40. Batiha GE-S, Beshbishy AM, Tayebwa DS, Adeyemi OS, Shaheen H, Yokoyama $\mathrm{N}$, et al. The effects of trans-chalcone and chalcone 4 hydrate on the growth of Babesia and Theileria. PLoS Negl Trop Dis. 2019a;13:e0007030.

41. Beshbishy AM, Batiha GE-S, Alkazmi L, Nadwa E, Rashwan E, Abdeen A, et al. Therapeutic effects of atranorin towards the proliferation of Babesia and Theileria parasites. Pathogen. 2020;9(2):E127.

42. Chandra D, Kohli G, Prasad K, Bisht G, Punetha VD, Khetwal KS, Devrani MK, Pandey HK. Phytochemical and ethnomedicinal uses of family Violaceae. Cur Res Chemi. 2015;7:44-52.

43. Alejo-Armijo A, Altarejos J, Salido S. Phytochemicals and biological activities of Laurel tree (Laurus nobilis). Nat Prod Comm. 2017;12:743-57.

44. Jasim SF, Baqer NN, Alraheem EA. Detection of phytochemical constituent in flowers of Viola Odorata by gas chromatography-mass spectroscopy. Asian J Pharm Clin Res. 2018;11(5):262-9.

45. Castaño Osorio JC, Giraldo García AM. Antiparasitic phytotherapy perspectives, scope and current development. Infectio. 2019;23(2):189-204.

46. Colares AV, Almeida-Souza F, Taniwaki NN, Souza C, da Costa JG, Calabrese K, Abreu-Silva AL. In vitro antileishmanial activity of essential oil of Vanillosmopsis arborea (Asteraceae) baker. Evid Based Complement Alternat Med. 2013;2013:727042.

47. Le TB, Beaufay C, Nghiem DT, Pham TA, Mingeot-Leclercq MP, QuetinLeclercq J. Evaluation of the anti-trypanosomal activity of vietnamese essential oils, with emphasis on Curcuma longa L. and its components. Molecules. 2019:24:1158.

48. Sharma UK, Sharma AK, Gupta A, Kumar R, Pandey A, Pandey AK. Pharmacological activities of cinnamaldehyde and eugenol: antioxidant, cytotoxic and anti-leishmanial studies. Cell Mol Biol (Noisy-le-grand). 2017; 63(6):73-8

49. Luna EC, Luna IS, Scotti L, Monteiro AFM, Scotti MT, de Moura RO, de Araújo RSA, Monteiro KLC, de Aquino TM, Ribeiro FF, Mendonça FJB. Active essential oils and their components in use against neglected diseases and Arboviruses. Oxidative Med Cell Longev. 2019;2019:6587150.

\section{Publisher's Note}

Springer Nature remains neutral with regard to jurisdictional claims in published maps and institutional affiliations. 